\title{
ТИПОМОРФНЫЕ ОСОБЕННОСТИ ЦИРКОНА В БАЗАЛЬНЫХ ОТЛОЖЕНИЯХ ОСАДОЧНОГО ЧЕХЛА СЕВЕРНОЙ ПРИБАЛТИКИ
}

Акцессорный циркон терригенных отложений является ценным источником информации об исходном материале их формирования.

Ранее нами изучены общие вопросы эволюции и унаследованности минерального состава вендских и кембрийских терригенных отложений (Вийдинг и др., 1983), дано сравнительное описание состава акцессорных минералов главных типов пород фундамента и базальных отложений осадочного чехла (Конса, Вийдинг, 1983), выявлены типоморфные особенности циркона пород кристаллического фундамента (Конса, 1986) и коры выветривания на фундаменте в зависимости от состава исходных пород (Конса, 1986). В настоящей статье рассматриваются результаты изучения типоморфных особенностей циркона из базальных слоев осадочного чехла - в отложениях венда и кембрия, и проводится сравнение с цирконами подстилающих пород фундамента и коры выветривания по конкретным изученным районам. Методика исследования была проведена согласно принципам, приведенным в работах Х. Вийдинга (Вийдинг, 1965, 1976; Вийдинг, Конса, 1976) с некоторыми изменениями применительно к породам фундамента (Клейн, Конса, 1986). Для исследований типоморфизма под микроскопом использованы выделенные при иммерсионном анализе цирконы в количестве 400-500 зерен, размерами $0,1-0,05$ мм. Местонахождение изученных скважин показано на рис. 1 и 2 в книге «Кристаллический фундамент Эстонии» (1983).

Как известно, на выровненной поверхности остаточной коры выветривания фундамента (архей, нижний протерозой) залегают различного возраста отложения верхнего венда и нижнего кембрия. Наиболее древние базальные отложения в Северо-Восточной Эстонии представлены оруской и молдоваской пачками гдовской свиты (Менс, Пиррус, 1980). На юго-западе территории на фундаменте залегают отложения балтийской, ливской и, наконец, в Западной Латвии - айсчяйской серий нижнего кембрия.

Разрезы оруской п а ки изучены на разнотипных породах фундамента. В поле распространения архейских гранитогней сов (ч а рнокитов) в Юго-Восточной Эстонии пачка пробурена скважинами 423 (Пылва) и 555 (Әлва). В разрезе скв. 423 изучены две пробы в интервале $546,0-547,0$ м непосредственно над фундаментом, а в скв. 555 - три пробы в интервале $499,0-502,8$ м.

В этих разрезах (табл. I, 2-1-7) оруской пачки большинство зерен циркона представлено в виде панидиоморфных сильно трещиноватых кристаллов, содержащих множество включений. Отдельные кристаллы прозрачные, ясные. Зональность встречается редко (в скв. 423 несколько чаще). Весьма характерны кристаллы с «ядрами» и выростами. Ядра, как правило, округленные, полуокругленные и панидиоморфные. Нередко в них наблюдаются еще внутренние ядра. Ядра обычно полупрозрачные трещиноватые и богатые включениями. Таким образом, в одном зерне можно установить три генерации циркона. 
В рассматриваемых скважинах встречаются также полуокруглленные, редко округленные, часто метамиктные трещиноватые зерна циркона с частыми включениями. Нередко циркон представлен в виде беспорядочных обломков (неправильные зерна).

Сравнивая охарактеризованный выше циркон из отложений оруской пачки с цирконом непосредственно нижезалегающих гранитогнейсов (чарнокитов) (табл. I, $a-1-7)$, обнаруживается их сходство. В коре вывётривания и в самом фундаменте встречаются такие же панидиоморфные сильно трещиноватые кристаллы с включениями, ядрами и выростами, а также с двумя разновозрастными ядрами. Таким образом, все три генерации циркона имеют архейский возраст. В то же время, количество неправильных обломков циркона в оруской пачке больше, чем в фундаменте, что указывает на растрескивание во время транспортировки и переотложения в осадочную породу. Следовательно, в данном примере источник исходного материала оруской пачки является очевидным - это кора выветривания архейских пород - нижезалегающих гранитогнейсов (чарнокитов).

Цирконы оруских отложений на коре выветривания чередующихся биотит-амфиболовых гнейсов и биотитовых пла ги огн ейсов нижнего протерозоя (табл. I, $\partial-1-6$ ) изучены по разрезу скважин Ф-159 (Вохнья) в двух пробах из интервала $254,4-$ 256,0 м над поверхностью фундамента (Тапаская зона, Северная Эстония). Большинство (60\%) зерен циркона встречается здесь в виде неправильных зерен и обломков, много и панидиоморфных кристаллов $(30 \%)$. Полуокругленные кристаллы встречены в количестве до $15 \%$. Циркон обычно бесцветный, иногда с желтоватым оттенком, прозрачный или полупрозрачный с частыми включениями, нередко трещиноватый и корродированный. Часть циркона метамиктизирована. Ядра и зональность не характерны. Отложения в оруской пачке в скв. Ф-159 залегают непосредственно над сильно выветрелыми биотит-амфиболовыми гнейсами, но цирконы оруской пачки здесь больше напоминают цирконы из биотитовых плагиогнейсов, которые обычно переслаиваются амфиболитовыми гнейсами. Циркон плагиогнейсов (табл. I, б-1-6) представлен панидиоморфными и полуокругленными полупрозрачными, иногда метамиктными, часто трещиноватыми кристаллами. Иногда видна зональность, сравнительно много включений. Цирконы с ядрами не характерны.

Оруские отложения, покрывающие непосредственно глинозе мисты и биотитовые гнейсы (табл. I, e-1-7) изучены в разрезах скважин Ф-199 (Сонда) - две пробы из интервала 236,5-237,0 м; Ф-187 (Мийла) - одна проба из интервала 267,5-267,9 м; Ф-190 (Эрра) - две пробы из интервала 228,3-228,7 м; Ф-144 (Линнузе) - одна проба из интервала $206,0-206,5$ м и Ф-153 (Амбла) - две пробы из интервала $317,2-317,6$ м.

В этих разрезах, кроме последнего (Ф-153), широко распространяются полуокругленные и округленные зерна циркона, но рядом с ними часто встречаются также неправильные обломки кристаллов. Панидиоморфных разностей сравнительно мало. Сильно преобладают непрозрачные или полупрозрачные метамиктные кристаллы с обильными включениями, часто трещиноватые. Зональность слабо выражена или отсутствует. Встречаются кристаллы с ядрами и выростами.

Такие особенности весьма характерны также циркону подстилающих биотитовых и глиноземистых гнейсов фундамента (табл. I, в-1-7). В них установлено присутствие большого количества реликтовых окатанных зерен циркона и кристаллов со следами окатывания или окатанными ядрами. Разница лишь в том, что в оруской пачке гораздо чаще встречаются неправильные обломки минерала. 
Йсключением являются отложения оруской пачки в разрезе скв, $\Phi-153$, где циркон панидиоморфный $(70-75 \%)$, полупрозрачный с многочисленными включениями, нередко метамиктный, зональный. Полуокругленные и неправильные зерна встречаются реже. Эти особенности циркона оруских отложений не характерны для непосредственно подстилающих биотитовых гнейсов, а сходны с цирконом теневых гранитов, выходы которых распространены непосредственно восточнее скв. Ф-153. По всей вероятности они и служили основным источником сноса для рассматриваемого района. Циркон в теневых гранитах характеризуется преобладанием панидиоморфных разновидностей. Кристаллы полупрозрачные, с многими включениями.

Таким образом, характерной особенностью цирконов в самом основании венда Эстонии (оруская пачка) является их относительно большое разнообразие, существенные локальные различия и большое сходство с цирконами пород кристаллического фундамента, залегающих непосредственно ниже или рядом. Следовательно, в цирконах оруской пачки хорошо отражается их наследственность от исходных пород.

Молдов аск а я п а ч ка является основной составной частью гдовской свиты и распространяется широко на территории Эстонии. Циркон (таблица, ж-1-12) изучен нами в основном из нижних уровней конгломератов и песчаников пачки. Всего проанализировано 33 пробы из 16 разрезов. В 11 разрезах рассматриваемая пачка залегает непосредственно на кристаллическом фундаменте, в остальных - на оруской пачке.

По сравнению с породами оруской пачки, где циркон отличается большим разнообразием и существенными различиями по латерали, в рассматриваемой пачке циркон характеризуется тождественными свойствами во всех исследованных пробах. Не выявляется существенных различий у цирконов из нижней или верхней части молдоваской пачки, а также из отложений, залегающих непосредственно на фундаменте или на оруской пачке.

Наибольшим распространением в молдоваских отложениях пользуются панидиоморфные короткопризматические бесцветные или желтоватые кристаллы, нередко в разной степени корродированные и трещиноватые, с многочисленными включениями, иногда мутные и с нечетко выраженной зональностью. Панидиоморфные кристаллы очень часто содержат полуокругленные или округленные ядра более темного циркона. Встречаются кристаллы сросшиеся и с наростами. Широко распространены также зерна циркона неправильной формы, обломки растрескивавшихся кристаллов с внутренним строением, аналогичным панидиоморфным. Из всего количества зерен циркона $10-20 \%$ полуокругленные, менее трещиноватые с частыми включениями и редкой зональностью. Ограниченно $(<5 \%)$ встречены идиоморфные, прозрачные и бесцветные кристаллы, нередко игольчатой формы.

Приведенная характеристика типоморфных разновидностей циркона хорошо подтверждает выводы, сделанные по анализу общего минерального состава молдоваской пачки (Конса, Вийдинг, 1983) и заключающиеся в том, что источником обломочного материала для пород пачки служили в основном средневыветрелые породы различного состава глиноземистые и биотитовые гнейсы, средние и основные изверженные породы и др.

Отложения балтий ской сери и нижнего кембрия, залегающие непосредственно на кристаллическом фундаменте в западных районах Эстонии, изучены по разрезу скв. 173 (Селисте) - две пробы из интервала 567,6-568,0 м. На сильно выветрелых двупироксеновых гнейсах залегают здесь песчаники и алевролиты наиболее древней части нижнего кембрия - таэблаской пачки воози ской свиты. Циркон 
(табл. IIA, б-1-6) встречается в них либо в виде панидиоморфных и идиоморфных (до 38 и $7 \%$ соответственно) зерен с многочисленными включениями (в большинстве случаев он трещиноватый, илогда зональный), либо в виде неправильных обломков (до $40 \%$ ). Количество полуокругленных зерен циркона достигает $12 \%$ от циркона всей пробы. Иногда полуокругленные зерна составляют ядра в панидиоморфных кристаллах.

Вышеотмеченное позволяет предполагать, что определенное сходство циркона базальных слоев кембрия с цирконом пород подстилающего фундамента (табл. IIA, $a-1-7$ ) в данном разрезе довольно хорошо улавливается (ассоциация панидиоморфного трещиноватого циркона с большим количеством включений, иногда с ядрами и неправильного циркона с наличием полуокругленных зерен), хотя присутствие идиоморфных и множества панидиоморфных зерен указывают на частичный привнос материала из источников иного петрографического состава.

В Западной Латвии, в разрезе скв. 54 (Колка) изучены две пробы в интервале 907,7-909,5 м при глубине поверхности фундамента 910,0 м, и в скв. 55 (Талсы) - две пробы в интервале $1122,0-1123,0$ м непосредственно на фундаменте. Базальные образования осадочного чехла принадлежат здесь к сыруской свите ливской сери и и подстилаются рапакиви-гранитами Рижского плутона. В большинстве случаев циркон (табл. ІІБ, б-1-6) встречается там в виде кристаллов неправильной формы. Присутствуют панидиоморфные призматические, обычно прозрачные и бесцветные или светлоокрашенные кристаллы, нередко с пониженным двупреломлением. Зональность в них выражена слабо. Часто встречаются уплощенные, как будто сросшиеся кристаллы очень характерные для гранитов типа рапакиви. Некоторые кристаллы содержат ядра метамиктно измененного циркона. Часто встречаются также корродированные зерна минерала.

Преобладание такого циркона явно указывает на основной источник циркона базальных слоев кембрия - это непосредственно подстилающие рапакиви-граниты огромного Рижского плутона, где циркон отличается своей правильной формой кристаллов (табл. ІІБ, $a-1-7)$. Однако, кроме панидиоморфного циркона распространяются также полуокругленные и округленные цирконы со многими включениями, но без заметной трещиноватости. Әто, несомненно, указывает на привнос части материала из других источников.

Базальные образования а й сч я й с ко й се р и и изучены по разрезу скв. 500 (Рухну) (табл. ІІВ, б-1-7) в одной пробе в интервале 783,9784,3 м непосредственно на поверхности фундамента. Низы данного разреза сложены соэл а с ко й с в то й. Подстилающими породами фундамента являются граниты (табл. IIB, $a-1-8$ ). В базальных слоях осадочного чехла данного разреза сильно преобладают (до $70 \%$ ) кристаллы циркона неправильной формы. Множество зерен без трещин, бесцветные, реже встречаются зерна с трещинами; включения мелкие. Панидиоморфные и полуокругленные зерна встречаются реже.

Отмеченные признаки циркона не указывают на непосредственно унаследованный характер рассматриваемой ассоциации. Преобладание неправильных зерен указывает на влияние динамического фактора; отсутствие каких-либо специфических особенностей - на переотложение и сильное смешивание материала из разных источников.

У ускюлаская пачка гдовской св иты, уже не имеющая контакта с кристаллическими породами, широко распространена в восточных районах Эстонии, постепенно выклиниваясь к западу.

Циркон этой пачки изучен в 45 пробах уускюласких пород из керна 18 буровых скважин. Ему характерна бесцветность и прозрачность кристаллов, с одной стороны, (табл. I, з-1-11) и значительное количе- 
ство корродированных зерен, с другой. Чаще встречаются панидиоморфные бесцветные прозрачные трещиноватые или, реже, нетрещиноватые кристаллы, иногда зональные, редко с ядрами, уплощенные, словно сросшиеся зерна. Панидиоморфные кристаллы образуют до $60 \%$ от общей массы циркона, иногда преобладают обломки неправильной формы. Идиоморфные прозрачные, иногда игольчатые кристаллы встречаются в количестве до $10 \%$. Редко они трещиноватые, с включениями. Округленные зерна практически отсутствуют, полуокругленных зерен обычно 5-15\%.

Приведенные особенности циркона уускюлаской пачки, так же как и характер минерального состава пород, показывают, что при формировании рассматриваемых отложений первостепенную роль играли сравнительно слабовыветрелые кристаллические породы различного состава. В редких случаях, вероятно, можно более определенно установить тип породы главного источника сноса. Например, в разрезе скв. Ф-199 (Ульясте) частые уплощенные и сросшиеся правильные кристаллы циркона имеют специфические особенности для циркона из гранитов типа рапакиви.

Отложения котлин ской с в и ты залегают на породах гдовской свиты и соответствуют трансгрессивной стадии развития седиментационного бассейна. Они не контактируют с кристаллическим основанием региона, а отделены от его выхода полосой распространения отложений гдовской свиты. Циркон в этих отложениях (табл. I, $u-1-10$ ) изучен в 13 пробах из 9 разрезов. По своему внешнему облику и основным особенностям внутреннего строения он относительно близок к циркону нижележащих отложений уускюлаской пачки, но отличается от последнего меньшим количеством окатанного циркона. Округленные зерна практически отсутствуют, полуокругленных меньше $10 \%$, панидиоморфных до $50 \%$, идиоморфных до $10 \%$ из всего количества циркона. Довольно часто встречаются обломки неправильной формы. Кристаллы бесцветные и прозрачные, часто трещиноватые, довольно часто и зональные; метамиктные цирконы весьма редкие. Большинство кристаллов содержит включения, ядра попадаются редко. Часто кристаллы циркона корродированы.

Циркон котлинской свиты заметно отличается от описанных выше в скв. 423 (Пылва). В этом разрезе часто встречаются метамиктные, нередко полуокругленные зерна циркона. Обильны также кристаллы с темными ядрами. Эти особенности циркона, как и минеральный состав отложений (Mens, 1981), вероятно, указывают на близость локального источника, сложенного метаморфизованными породами.

В орон ков ска я с в т а соответствует регрессивной стадии поздневалдайского седиментационного цикла. Из песчаников и алевролитов воронковской свиты изучено 28 проб из 18 разрезов. Среди типоморфных разновидностей циркона (табл. I, $\kappa-1-9$ ) резко преобладают панидиоморфные и неправильные, часто корродированные зерна. Панидиоморфные кристаллы обычно короткопризматические, бесцветные, реже коричневатые или желтоватые, прозрачные или мутные, часто со многими включениями. Кристаллы менее трещиноватые, чем в подстилающей свите. Несколько уменьшается количество идиоморфных зерен минерала; округленные зерна практически отсутствуют, полуокругленных также относительно мало, но по сравнению с котлинской свитой их роль увеличивается. В этих полуокругленных зернах циркона иногда встречаются ядра. Таким образом, циркон воронковской свиты отражает скорее химическое воздействие в ходе диагенеза в песчаниках, чем влияние истирания в течение транспортировки и переотложения подстилающих отложений, 


\section{Заключение}

Приведенными исследованиями установлено, что распределение типоморфных разновидностей цирконов носит существенную генетическую и палеогеографическую информацию об источниках сноса и особенностях формирования разновозрастных базальных отложений осадочного чехла.

1. Отложения самой древней оруской пачки венда, а также более молодые отложения нижнего кембрия (таэблаской пачки воозиской свиты, сыруской свиты, соэлаской свиты) в случаях непосредственного залегания на породах фундамента, содержат акцессорные цирконы, унаследованные прямо из подстилающего или смежных участков кристаллического фундамента. По этой причине типоморфные особенности циркона в латеральном направлении могут существенно меняться и служить индикатором конкретных путей привноса материала.

2. Отложения молдоваской пачки гдовской свиты венда, несмотря на частое непосредственное залегание на фундаменте, характеризуются более усредненными, унаследованными из разных типов кристаллических пород типоморфными особенностями циркона, что, вероятно, свидетельствует о длительной транспортировки материала до окончательной фиксации в конечных отложениях.

3. Вышележащие вендские отложения (уускюлаская пачка гдовской свиты, котлинская свита, воронковская свита), которые, как правило, не имеют контакта с породами кристаллического фундамента, имеют усредненное, но измененное по сравнению с молдоваскими отложениями распределение цирконов с различными типоморфными особенностями, что указывает на смешанный источник терригенного материала. Однако, при наличии близкорасположенных локальных или более обширных источников сноса кристаллических пород это может сразу же найти отражение в ассоциации разновидностей циркона (уускюлаская пачка в районе Ульясте, котлинская свита в Пылва).

4. Изменение цирконов уускюласких, котлинских и воронковских отложений, по сравнению с молдоваскими, заключается в уменьшении содержания зерен округленных, полуокругленных, метамиктных, трещиноватых и зерен с ядрами. В то же время возрастает относительное количество зерен корродированных, панидиоморфных, неправильных (образовавшихся путем разрушения цельных зерен), что, вероятно, свидетельствует о меньшей сохранности трещиноватых и метамиктных зерен в осадкообразовании и о наложенных процессах коррозии в песчаниках в стадии диагенеза. Помимо того, имеются также признаки новых источников материала, включающего новые типоморфные разновидности циркона.

\section{ЛИТЕРАТ У Р А}

Buйдине X. A. Некоторые методические вопросы литолого-минералогического анализа песчано-алевритовых пород Прибалтики. - Уч. зап. Тартуск. гос. ун-та. Тр. по геологин, III, 1965.

Вийдинг Х. Об ннтерпретацин данных минералогического анализа. - В кн.: Методика и интерпретация результатов минералогических и геохимических исследований.

Внльнюс, 1976, 53-59.
Вийдине Х. А., Клеесмент А. Э., Конса М. И., Хейнсалу Х. Н., Юргенсон Э. А. Эволюция мннерального состава терригенного компонента осадочного чехла на южном склоне Балтийского щита. - В кн.: Терригенные минералы осадочных пород Прибалтикн. Таллин, 1983, 7-22. 


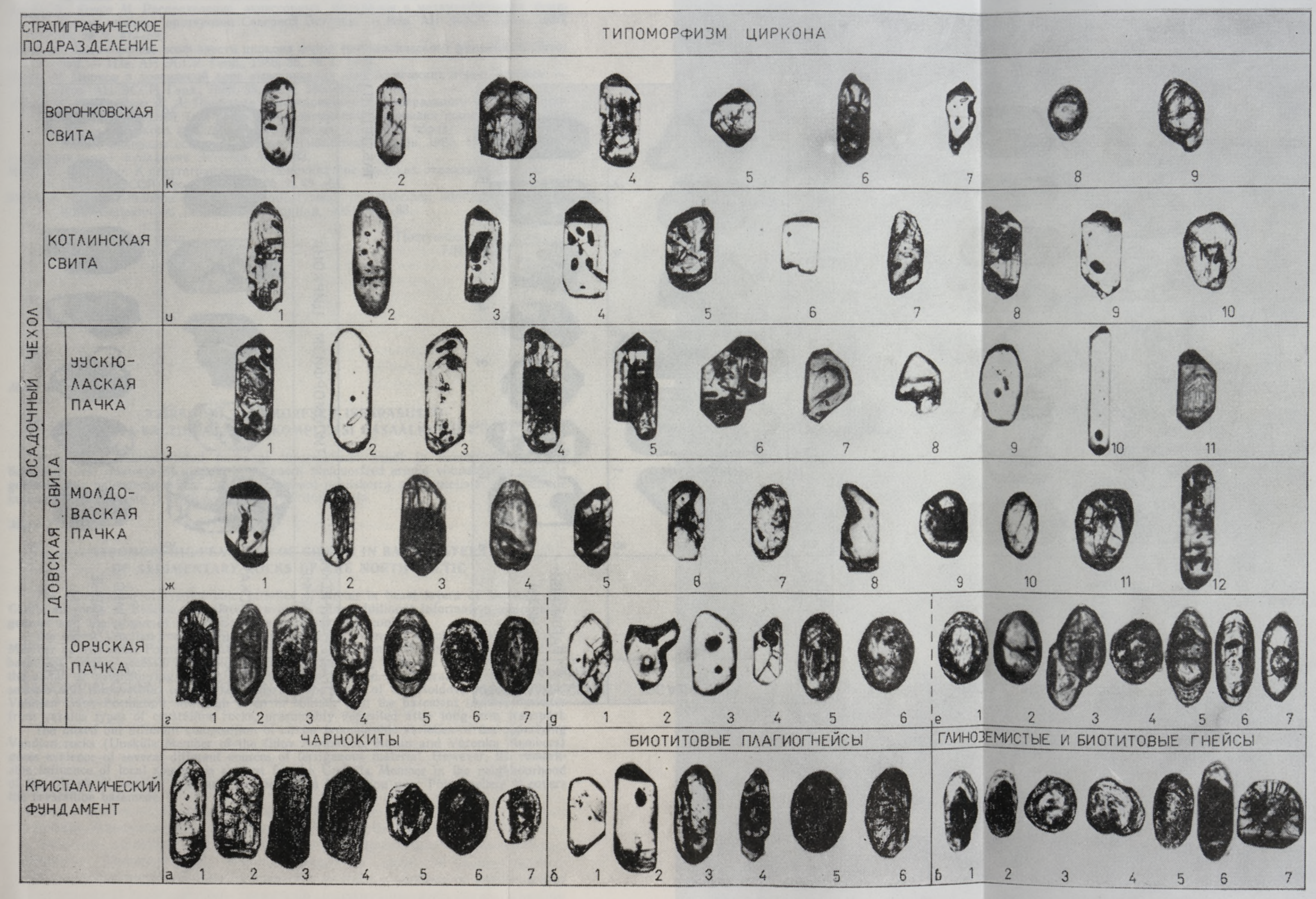



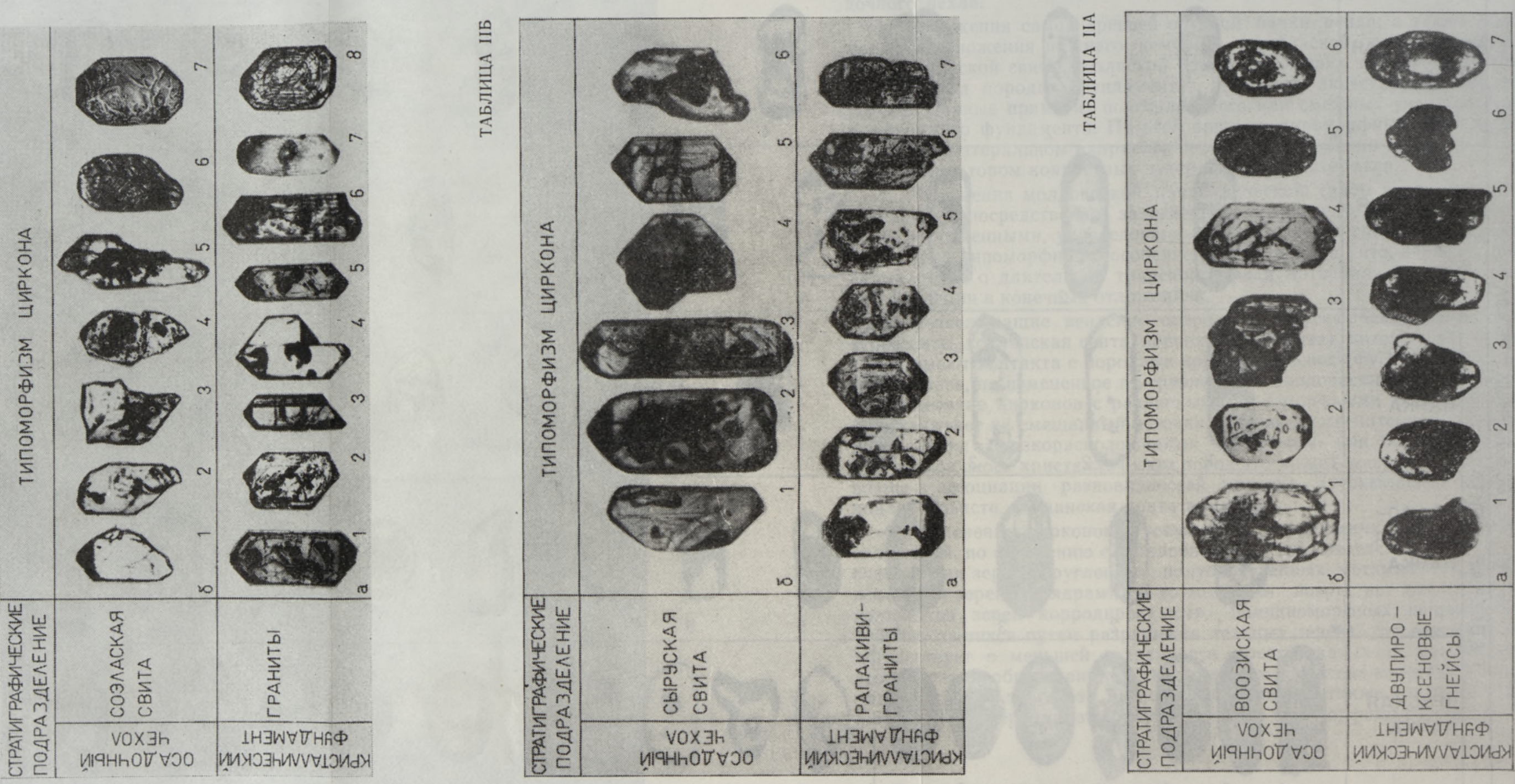
Bийдинг X., Конса М. Учет данных по типоморфным разновидностям минералов терригенных отложений. - В кн.: Методика и интерпретация результатов минералогических и геохимических исследований. Внльнюс, $1976,60-67$.

Клейн B., Конса М. Распределение акцессорных минералов. в метаморфических комплексах нижнего протерозоя Северной Эстонии. - Изв. АН ЭССР. Геол., 1986, 35, № 2, 47-52.

Конса М. Типоморфные особенности циркона пород кристаллического фундамента Эстонии. - Изв. АН ЭССР. Геол., 1986, 35, № 1, 1-9.

Конса М. Циркон в довендской коре выветривания кристаллических пород Эстонии. Изв. АН ЭССР. Геол., 1986, 35, № 4, 160-162.

Конса М. И., Вийдинг Х. А. Проблема унаследованности минерального состава терригенных отложений (на примере сравнительного изучения коры выветривания кристаллического фундамента и базальных осадочных пород). - В кн.: Терригенные минералы осадочных пород Прибалтики. Таллин, 1983, 41-48.

Кристаллический фундамент Эстонии. М., 1983.

Менс К., Пиррус Ә. К стратиграфической номенклатуре вендских отложений Эстонии. Изв. АН ЭССР, Геол., 1980, 29, № 2, 49-54.

Mens, $K$. Haanja-Mõniste struktuuri arengust vendi ja kambriumi läbilōigete alusel. Rmt.: Settekivimid ja tektoonika. Tallinn, 1981, 45-63.
Институт геологии
Академии наук Эстонской ССР
Поступила в редакцию
7/II 1986

Mare KONSA

\section{TSIRKOONI TUPOMORFSED ISEÄRASUSED \\ POHJA-BALTIKUMI SETTEKOMPLEKSI BASAALKIHTIDES}

Artiklis on iseloomustatud tsirkooni tüpomorfismi vendi ja kambriumi setendite basaalkihtides. Materjalist nähtub, et tsirkooni tüpomorfsed erimid võimaldavad hankida geneetilist ja paleogeograafilist lisainformatsiooni pealiskorra erivanuseliste basaalkihtide kujunemise iseärasuste ja terrigeense ainese päritolu kohta.

\section{Mare KONSA}

\section{TYPOMORPHIC FEATURES OF CIRCON IN BASAL LAYERS OF SEDIMENTARY ROCKS OF THE NORTH BALTIC}

The examination of typomorphic varieties of circon in basal layers of Vendian and Cambrian rocks of Estonia and Latvia revealed some additional information about their genesis and the origin of the terrigenous material they contain.

The oldest Vendian rocks (Oru Member) and the youngest Cambrian rocks (Taebla Member of the Voosi Formation, Sõru and Soela Formations), if lying on the crystalline basement contain accessory varieties of circon originating from the underlying rocks of the same or neighbouring territories which can be used as lateral indicators of the sources and transport of terrigenous material. The rocks of the Moldova Member of the Vendian Gdov Formation, although often in contact with the basement include varieties from various types of crystalline rocks, presumably deposited after long-term transport.

The mixed but different composition of circon typomorphic varieties of the upperlying Vendian rocks (Uusküla Member of the Gdov Formation, Kotlin and Voronka Members) gives evidence of several different sources of terrigenous material. However, the remarkable influence of local sources is evident for the Uusküla Member in the neighbourhood of the Uljaste dislocation zone and for the Kotlin Formation near Põlva, where it covers the crystalline basement. 